\title{
PENGAWASAN DALAM PENYELENGGARAAN PENDIDIKAN ANAK USIA DINI (PAUD) DESA DI KECAMATAN BENGKALIS KABUPATEN BENGKALIS
}

\author{
Irwan Safari \\ Isjoni \\ Zulfan Saam \\ 1)Post Graduate Student of Riau University \\ ${ }^{2}$ Lecturer of Education Management Study Programme PPs University of Riau \\ ${ }^{3}$ Lecturer of Education Management Study Programme PPs University of Riau
}

\begin{abstract}
Early childhood education management achievement determines the quality of education services to the kids who they are in the golden age as crucial times in their life, influencing of their next level education process. The aim of this research is to find out the achievement of early childhood education management in Bengkalis district. The research subfocuses are: 1) curriculum arrangement and application, 2) the human resources utilization, 3) facilities utilization, 4) financial management, and 5) institution network. This is a descriptive qualitative research, located at PAUD Kasih Bunda of Teluk Latak village and PAUD Cahaya Insan Penebal village of Bengkalis district. The data was gained through interview, observation, and document analizing. The informans are manegers, teachers, society man, parents, and nonformal early childhood education controller of Bengkalis district. Then, the collecting data was analized by interpretative approach.The results of this study shows that the curriculum management and application at both PAUD Kasih Bunda and PAUD Cahaya Insan could be categorized good, eventhough parents don't get contribution in teaching material development. Human resources which consist of the manegers, teachers of both early childhood education institutions are not categorized as academic standard provided. Then, both institutions of early childhood education has equiped faciclities for learning process, but it concerns to the lack of safety, not confortable, and healthy standard for the kids. Administration staff is not profesional yet, so that the financial management is not accuntable and transparancy. And the last found of both institutions have networking to somes small authorities in the villages without programs and written commitments.
\end{abstract}

Key Words: Early Childhood Education, Controlling

ABSTRAK: Pencapaian penyelenggaraan Pendidikan Anak Usia Dini merupakan gambaran kualitas pelayanan pendidikan terhadap anak pada masa yang sangat penting dalam kehidupannya, menentukan keberlangsungan pendidikannya pada masa dan tingkat selanjutnya. Penelitian ini bertujuan untuk mengetahui pencapaian penyelenggaraan PAUD nonformal desa di kecamatan Bengkalis. Sub fokus penelitian adalah: 1) Penyusunan dan penyelenggaraan kurikulum, 2) pendayagunaan tenaga pendidik dan kependidikan, 3) pendayagunaan sarana prasarana, 4) pendayagunaan ketatausahaan termasuk pengelolaan keuangan, dan 5) kemitraan lembaga PAUD nonformal desa dengan pihak luar yang relevan. Penelitian ini merupakan penelitian deskriptif kualitatif. Situs penelitian ini adalah PAUD kasih Bunda desa Teluk Latak dan PAUD Cahaya Insan desa Penebal kecamatan Bengkalis. Data dalam penelitian ini diperoleh dengan teknik wawancara, observasi, dan telaah dokumen dan melibatkan para informan; pengelola PAUD, guru PAUD, ketua BPD, wali murid, dan pengawas PAUD nonformal di UPTD Pendidikan Kecamatan Bengkalis. Selanjutnya data dianalisis data dilakukan dengan pendekatan 
interpretatif (interpretative approach). Hasil penelitian ini menunjukkan bahwa: 1) Penyusunan dan pelaksanaan kurikulum di kedua lembaga PAUD nonformal desa tersebut sudah baik, namun dalam hal pengembangan bahan ajar tidak melibatkan orang tua sesuai dengan prinsip yang terdapat pada Permendiknas No. 28 thun 2009 tentang PAUD, 2) Tenaga pendidik dan kependidikan belum memenuhi kualifikasi akademik yang dipersyaratkan, 3) Sarana dan prasarana sudah layak dari segi kelengkapannya, akan tetapi belum memenuhi prinsip aman, nyaman, dan memenuhi kriteria kesehatan bagi anak, 4) Ketatausahaan khususnya tenaga administrasi dirangkap oleh tenaga pendidik, sehingga pengelolaan administrasi dan keuangan belum mencapai prinsip transparan dan akuntabel, dan 5) PAUD norformal desa tersebut sudah menjalin kemitraan yang terbatas pada lingkup desa namun belum memiliki program kerja sama dan perjanjian tertulis.

Kata Kunci: Pendidikan Anak Usia dini, Pengawasan

\section{PENDAHULUAN}

Dalam Undang-Undang Nomor 20 tahun 2003 tentang Sisdiknas ditegaskan bahwa PAUD adalah suatu upaya pembinaan yang ditujukan kepada anak sejak lahir sampai usia enam tahun yang dilakukan melalui pemberian rangsangan pendidikan untuk membantu perkembangan dan pertumbuhan jasmani serta rohani agar anak memiliki kesiapan dalam memasuki pendidikan yang lebih lanjut.

Selanjutnya dalam Permendiknas nomor 58 tahun 2009 tentang standar Pendidikan Anak Usia Dini, dikemukakan bahwa PAUD diselenggarakan sebelum jenjang pendidikan dasar melalui jalur formal, nonformal, dan informal. Pada jalur formal berbentuk Taman Kanak-Kanak (TK), Raudatul Athfal (RA), dan bentuk lain yang sederajat. Pada jalur nonformal berbentuk Kelompok Bermain (KB), Taman Penitipan Anak (TPA), sedangkan pada jalur informal berbentuk pendidikan keluarga dan pendidikan yang diselenggarakan oleh lingkungan.

Berkenaan dengan hal tersebut, belakangan ini perhatian pemerintah dan masyarakat terhadap Pendidikan Anak Usia Dini (PAUD) mengalami peningkatan yang cukup signifikan. Pertumbuhan jumlah lembaga-lembaga yang menaungi PAUD yang begitu pesat tentunya perlu mendapatkan apresiasi. Sebab eksistensinya menggambarkan pemahaman dan kesadaran semua pihak tentang urgensi PAUD bagi tumbuh kembang anak sebagai generasi penerus. PAUD memberikan kontribusi yang sangat positif melalui rangsangan pendidikan terhadap pertumbuhan anak. Sehingga diharapkan terjadinya perkembangan dan pertumbuhan yang optimal dengan akses yang dilakukan oleh seluruh kalangan masyarakat dengan standar yang tepat.

Oleh karena itu pemerataan jumlah lembaga PAUD di seteiap daerah sangat diperlukan. Hal ini senada dengan apa yang disampaikan oleh Suyadi (2012) dalam bukunya yang berjudul “Manajemen PAUD TPA-KB/TK-RA” sebagai berikut:

"Keberadaan PAUD di setiap wilayah, minimal setiap $R W$ menjadi keniscayaan. Sebab, jika wilayah yang lebih luas dari $R W$, kelurahan, misalnya, hanya terdapat beberapa PAUD dan keberadaanya tidak tersebar rata, maka banyak anak yang tidak mampu menjangkaunya".

Berdasarkan pendapat Suyadi tersebut, sudah tepatlah kiranya bila di setiap RW terdapat pusat-pusat penyelenggaraan PAUD. Tujuannya adalah terjaminnya kesempatan bagi seluruh anak usia PAUD untuk memperoleh rangsangan pendidikan dalam menggiring pertumbuhannya baik pisik maupun mental. Masa depan seorang anak tidak terlepas dari perkembangan dan pertumbuhan anak sejak lahir, dimana perkembangan dan pertumbuhannya akan menjadi optimal jika mendapat rangsangan dari lingkungan baik berupa rangsangan eksternal maunpun internal. 
Dari hasil wawancara awal dengan pengawas PAUD nonformal di UPTD Pendidikan kecamatan Bengkalis diperoleh informasi bahwa di kecamatan Bengkalis terdapat lebih kurang 52 lembaga PAUD nonformal yang telah terdaftar. Lembaga PAUD ini berdiri untuk memenuhi kebutuhan masyarakat terhadap layanan pendidikan anak usia dini di setiap desa. Jadi setiap desa memiliki minimal satu lembaga PAUD nonformal desa yang berjalan dengan support dari dana ADD desa disamping sumber lain dari pemerintah dan masyarakat.

Namun pada kenyataannya dilapangan penyelengaraan PAUD nonformal desa ini belum terpantau secara optimal dan terkesan dibiarkan berjalan begitu saja. Dari informasi awal yang diperoleh dari pengawas PAUD nonformal kecamatan Bengkalis, bahwa fenomenanya hampir seluruh PAUD nonformal desa di kecamatan Bengkalis belum terakreditasi dan tidak memiliki hasil evaluasi tentang sejauh mana pencapaian standar PAUD nonformal yang telah ditetapkan. Penyelenggaraan PAUD nonformal ini masih berorientasi kepada pemenuhan kebutuhan akan akses pendidikan anak usia dini di desa-desa dengan stimulasi terhadap kuantitas lembaga dan belum optimalnya kajian terhadap ketercapaian standar PAUD nonformal itu sendiri. Hal ini tentunya mempengaruhi kualitas pelayanan pendidikan anak usia dini bagi keberlangsungan pendidikan di tengah masyarakat.

Jamal (2009) menjelaskan bahwa suatu lembaga pendidikan agar dapat berjalan secara efektif dan efisien diperlukan adanya penataan, pengaturan, pengelolaan, dan kegiatan lain yang sejenis. PAUD yang baik dan berkualitas tentunya dikelola dan diselenggarakan dengan menerapkan fungsi manajemen mulai dari perencanaan, pengorganisasian, pengarahan, dan pengawasan. Fungsi-fungsi manajemen tersebut mengacu kepada optimalisasi sumber daya pendidikan diantaranya sumber daya manusia, sarana prasarana, kurikulum, dan pembiayaan. Hal ini sesuai dengan apa yang disampaikan oleh Jamal (2009) dalam bukunya yang berjudul
“Manajemen Strategis PAUD”, sebagai berikut:

"Mengelola pendidikan bukanlah mengelola sebuah tempat usaha barang, melainkan mengelola sumber daya manusia yang memiliki keunikan- keunikan masingmasing. Untuk itu dibutuhkan formula yang tepat dalam mengatur segala permasalahan manajemen pendidikan anak usia dini (PAUD)".

Oleh sebab itu diperlukan sistem pengawasan yang baik agar dalam praktiknya PAUD ini berjalan sesuai dengan standar kebutuhan pelayanan pendidikan terhadap anak usia dini. Pengawasan menurut Sobry ( 2012) berkenaan dengan kegiatan membandingkan antara kondisi nyata dengan standar apa yang telah ditetapkan. Sobry (2012) menambahkan bahwa pengawasan terhadap organisasi pendidikan, dalam hal ini lembaga PAUD nonformal mencakup pengendalian dan penilaian terhadap kurikulum, pendayagunaan pendidik dan kependidikan, pendayagunaan sarana dan prasarana, ketatausahaan atau pengelolaan keuangan, dan kemitraan lembaga dengan pihak luar.

Aedi (2014) mendefinisikan pengawasan adalah suatu proses sistematis dalam memastikan proses pendidikan berjalan sesuai dengan rencana dan standar yang telah ditentukan sehingga ada sebuah cerimanan tentang pencapaian tujuan pendidikan itu sendiri. Dengan demikian dapat disimpulkan bahwa pengawasan mengandung makna membandingkan situasi yang ada dengan apa yang seharusnya terjadi untuk selanjutnya dilakukan pembinaan, bimbingan, dan dorongan untuk melakukan perbaikan terhadap ketimpangan-ketimpangan yang terjadi. Melalui pengawasan diharapkan kegiatan atau pekerjaan yang sedang atau akan berlangsung dapat lebih baik mengacu kepada apa yang telah disepakati dan ditetapkan sebagai rencana atau standar kerja. Dengan demikian, ketercapaian standar penyelenggaraan PAUD Nonformal desa di kecamatan Bengkalis ini menjadi masalah yang menarik untuk diteliti secara kualitatif. 


\section{METODE PENELITIAN}

Penelitian ini bersifat empiris karena berdasarkan data-data dari lapangan. Peneliti akan berupaya mengumpulkan berbagai bentuk data dari situs penelitian. Karena itu, pendekatannya adalah penelitian kualitatif. Dalam prosesnya di lapangan, penelitian ini bersifat fleksibel, tergantung pada kondisi dan situasi di lapangan ataupun juga situasi dan kondisi situs penelitian.

Sejalan dengan pendapat di atas, Bogdan dan Taylor yang dikutip oleh Basrowi (2008) mengatakan bahwa penelitian kualitatif merupakan salah satu prosedur penelitian yang menghasilkan data deskriptif berupa ucapan, tulisan, dan perilaku para partisipan. Selain itu Hamid (2011) menegaskan beberapa hal yang perlu diperhatikan dalam penelitian kualitatif. Pertama, lebih menekankan perhatian kepada proses, bukan pada hasil atau produk. Kedua, tertarik pada makna, yaitu bagaimana orang membuat hidup, pengalaman, dan struktur kehidupannya masuk akal. Ketiga, peneliti merupakan instrumen pokok untuk pengumpulan data dan analisis data. Keempat, melibatkan kerja lapangan. Peneliti secara fisik berhubungan dengan orang, latar belakang, lokasi atau institusi untuk mengamati atau mencatat perilaku dalam latar alamiahnya. Kelima, bersifat deskriptif. Dan yang keenam proses penelitian bersifat induktif, peneliti membangun abstrak, konsep, proposisi, dan teori.

Selanjutnya, dengan penentuan informan dalam penelitian kualitatif tentu berbeda dengan sampel pada penelitian kuantitatif. Penelitian kualitatif pada umumnya menggunakan sampel bertujuan (purposive sampling). Dalam sampel bertujuan peneliti dengan sengaja memilih individu-individu atau situs-situs guna mempelajari atau mengetahui fenomena sentral. Jadi situs penelitian ini adalah lembaga PAUD Kasih Bunda desa Teluk Latak, dan PAUD Cahaya Insan desa Penebal kecamatan Bengkalis. Kedua situs ini tentunya dapat memenuhi kebutuhan peneliti terhadap informasi penyelenggaraannya dalam menggali fenomena sentral, yang sudah jelas sarat dengan informasi.
Selanjutnya data dalam penelitian ini merupakan data hasil wawancara, pengamatan, dan telaah dokumen yang melibatkan peneliti sendiri dan para informan. Data primer penelitian ini berkaitan dengan fokus penelitian, yaitu pengawasan dalam penyelenggaraan PAUD nonformal desa di kecamatan Bengkalis. Oleh sebab itu peneliti berusaha memperoleh data dalam penelitian ini dari kepala sekolah/pengelola PAUD nonformal desa, guru-guru, ketua BPD, wali murid, dan pengawas PAUD nonformal di UPTD Pendidikan kecamatan Bengkalis. Acuan dalam pengembangan pedoman wawancara, observasi dan telaah dokumen meliputi; 1) penyusunan dan pelaksanaan kurikulum, 2) pendayagunaan tenaga pendidik dan kependidikan, (3) pendayagunaan sarana dan prasarana, (4) pendayagunaan ketatatusahaan dan pengelolaan keuangan, dan (5) kemitraan lembaga dengan pihak luar.

Analisis data merupakan kegiatan menemukan dan mengorganisasikan data yang diperoleh dari transkrip wawancara, observasi, dan telaah dokumen untuk kemudian disajikan kepada orang lain. Jadi dengan demikian analisis data dalam penelitian ini peneliti menggunakan model Bogdan dan Biklen dengan langkahlangkah penelitian sebagai berikut:

1. Mencatat hasil penelitian yang diperoleh baik melalui observasi, wawancara, maupun dalam bentuk trasnkrip hasil telaah dokumen.

2. Setelah ditafsirkan lalu data dipilah-pilah kedalam kategori-kategori untuk menajamkan serta mengarahkan dan membuang yang tidak penting.

3. Mengklasifikasikan data-data tersebut sesuai dengan sub-fokus penelitian.

4. Menganalisis data-data tersebut dan memberikan interpretasi terhadap data yang diperoleh dengan cara memberikan penjelasan yang bersifat kualitatif.

5. Membuat kesimpulan agar maksud dari penelitian dapat memberi arti. 


\section{HASIL DAN PEMBAHASAN}

1. Penyusunan dan Pelaksanaan Kurikulum

Dalam Permendiknas No. 49 tahun 2007 tentang standar pengelolaan pendidikan oleh satuan pendidikan Nonformal dinyatakan setiap satuan pendidikan Nonformal bertanggung jawab atas tersusunnya kurikulum dan atau rencana pembelajaran. Penyusunan kurikulum ini dilakukan dengan memperhatikan Standar Isi dan Standar Kompetensi yang telah ditentukan.

Berdasarkan data dan informasi yang berhasil dikumpulkan dalam penelitian ini di PAUD Kasih Bunda desa Teluk Latak, dan PAUD Cahaya Insan desa Penebal kecamatan Bengkalis, dapat dianalisis bahwa lembaga PAUD Nonformal desa ini melakukan penyusunan kurikulum secara mandiri. Pengelola bersama guru-guru PAUD menyusun kurikulum dengan berpedoman kepada Standar Isi yang ada di kurikulum nasional PAUD. Penyusunan kurikulum dilakukan dengan mempertimbangkan karakteristik anak di desa Teluk Latak sesuai dengan tahap perkebangan usianya. Hal ini dilakukan agar dapat dibangun perkembangan yang komprehensif, kurikulum dapat menyediakan layanan interaksi dan kegiatan berdasarkan usia dan kondisi pisik dan psikologis anak usia dini di desa.

Namun PAUD Kasih Bunda desa Teluk Latak dan PAUD Cahay Insan desa Penebal belum melibatkan orang tua dalam penyusunan kurikulum. Orang tua pada dasarnya adalah pendidik utama bagi anak. Oleh sebab itu keterlibatan orang tua sangat diperlukan dalam mendesain kegiatan dan materi pembelajaran untuk optimalisasi pelayanan pendidikan yang diberikan kepada anak usia dini.

Analisis selanjutnya berkenaan dengan pelaksanaan kurikulum, yakni proses pembelajaran di PAUD kasih Bunda desa Teluk Latak yang juga tidak jauh berbeda dengan proses pembelajaran di PAUD Cahaya Insan desa Penebal, dilakukan dengan prinsip belajar sambil bermain, aktivitas belajar berpusat kepada anak, dan mengguanak metode yang bervariasi serta adanya media pembelajaran. Mulyasa
(2012) menjelaskan bahwa aktivitas bermain memang tidak bisa terlepas dari dunia anak usia dini. Melalui permainan mereka dapat belajar banyak hal, dapat mengenal aturan, bersosialisasi, menata emosi, toleransi, kerja sama, dan menjunjung tinggi nilai sportivitas. Bagi anak usia dini sebanarnya sangat sulit mencari aktivitas sebagai pengganti bermain. Sehingga guru harus jeli dan bijaksana memilih dan menggunakan metode sekaligus media pembelajaran sehingga aktivitas bermain memang menjadi wadah yang tepat dalam menyampaikan materi pembelajaran.

Kemudian evaluasi pembelajaran di kedua lemabaga PAUD Nonformal desa dia atas dilakukan selama proses berlangsung dengan tanya jawab, mencatat hasil penilaian ke dalam buku catatan perkembangan anak, dan melaporkan kepada orang tua melalui buku penghubung serta dijadikan dasar pengembangan program berikutnya. Dengan demikian ada dasar pengukuran terhadap pencapaian program pembelajaran yang mencakup pembiasaan dan keteladanan yang berwujud kedalam perilaku anak sehari-hari, informasi tentang perkembangan bahasa, daya cipta, emosional, dan keterampilan jasmani, dan penelususran bakat dan minat anak yang selanjutnya secara bersama antara orang tua dan guru dapat mengambil keputusan tentang kebutuhan dan perkembangan anak. Disamping itu juga evaluasi dapat merefleksikan masalah atau kesulitan yang dialami anak dalam perkembangan dan pertumbuhannya.

Sebagaimana pendapat Mulyasa (2012) bahwa evaluasi atau penilaian pendidikan anak usia dini penting dilakukan untuk mengetahui seberapa besar dampak program pendidikan terhadap perilaku dan sikap, baik jangka pendek, menengah, maupun jangka panjang. Hasil pengamatan terhadap perilaku dan sikap anak yang terekam didalam catatan perkembangan anak dapat dijadikan standar bagi orang tua dan guru. Baik dalam menentukan bentuk beimbingan dan pengasuhan berikutnya maupun dalam menumbuhkan bakat dan minat yang sesuai dengan apa yang ada pada diri anak. 
2. Pendayagunaan Tenaga Pendidik dan kependidikan

Temuan penelitian ini di PAUD Kasih Bunda desa Teluk Latak dan PAUD Cahaya Insan desa Penebal bahwa PAUD Nonformal desa ini digerakkan oleh sumber daya manusia yang terdiri dari satu orang pengelola (kepala PAUD), 4-6 orang guru yang dua diantaranya sekaligus bertugas sebagai tenaga administrasi yakni sekretaris dan bendahara PAUD (tenaga kependidikan), dan penilik atau pengawas PAUD Nonfromal.

Pengelola atau kepala dan empat orang guru PAUD Kasih Bunda desa Teluk Latak memiliki kualifikasi akademik tamatan SMA, dan satu orang gurunya berijazah sarjana pendidikan Islam (S.Pd.I). sedangkan pengelola (kepala) PAUD Cahaya Insan desa Penebal memiliki kualifikasi akademik sarjana pendidikan Islam (S.Pd.I), dua orang guru berijazah sarjana pendidikan (S.Pd), satu orang berijazah sarjana pendidikan SD (S.Pd.SD) dan tiga orang lainnya tamatan SMA sederajat.

Dengan demikian tenaga pendidik dan kependidikan di PAUD Kasih Bunda desa Teluk Latak dan PAUD Cahaya Insan desa Penebal belum memenuhi kualifikasi akademik yang dipersyaratkan. Sebagaimana Suyadi (2012) menjelaskan bahwa persyaratan kusus bagi kepala (pengelola) PAUD adalah memiliki kualifikasi akademik serendah-rendahnya S.1PGPAUD atau sederajat, dan memiliki pengalaman mengajar sekurang-kurangnya 5 tahun. Sedangkan persyaratan khusus untuk guru PAUD adalah memiliki ijazah serendahrendahnya S.1-PGPAUD, dan mampu bercerita, bernyanyi, dan bermain alat musik.

Hal ini tentunya mempengaruhi pelayanan di kedua lembaga PAUD Nonformla desa ini bagi kebutuhan pendidikan yang berkualitas. Sebagaimana Suyadi mengatakan bahwa kualitas dan profesionalitas penyelenggaraan lembaga PAUD sangat tergantung pada latar belakang pendidikan dan pengalaman pengelola PAUD, bidang keilmuan guru, dan tenaga profesional lainnya.
3. Pendayagunaan Sarana Prasarana

Sarana dan prasarana lembaga PAUD meliputi semua aset yang mencakup tanah dan bangunan PAUD, alat pembelajaran yang terdiri dari alat-alat permainan edikatif (APE) baik indoor maupun outdoor, serta alat-alat lainnya. Pendayagunaan sarana dan prasarana yang dikaji meliputi lokasi PAUD, luas tanah, perawatan dan pemanfaatannya.

PAUD Kasih Bunda desa Teluk Latak kecamatan Bengkalis adalah satu-satunya PAUD Nonformal desa yang berlokasi di jalan utama Dusun Simpang Baru. Lembaga PAUD Nonformal desa ini terletak di tengah-tengah pemukiman penduduk, sehingga akses ke lembaga PAUD ini cukup mudah. Namun berdasarkan temuan penelitian pada situs ini mengungkapkan bahwa PAUD Kasih Bunda desa Teluk Latak belum memiliki tanah dan bangunan sendiri. Tanah dan bangunan yang digunakan saat ini adalah tanah dan bangunan milik MDAdesa Teluk Latak. Proses pendidikan di PAUD Nonformal desa Teluk Latak hanya memanfaatkan ruang bangunan yang ada.

Di lahan seluas 32 × $40 \mathrm{M}$ dan gedung yang digunakan PAUD Kasih Bunda desa Teluk latak ini terdapat 2 ruang belajar, kantor, area bermain, tempat cuci tangan, dan kamar madi (toilet) dengan air bersih yang cukup. Artinya untuk luas lahan dan ruang serta prasarana pendukung lainnya yang digunakan PAUD Nonformal desa ini sudah sesuai dengan standar yang ada, akan tetapi disesbabkan oleh masalah kepemilikan, tata ruang dan gedung yang ada tidak dapat disesuiakan dengan kebutuhan penyelenggaraan PAUD.

Area bermain luar yang berisi APE luar terletak disudut lahan dengan ukuran $8 \times 8 \mathrm{M}$. APE luar yang ada di PAUD Kasih Bunda desa Teluk Latak ini berupa 2 unit kursi jungkit, 2 unit ayunan gantung, dan 2 unit papan jungkit dari kayu. Kondisi APE luar ini kurang terawat, diamana ada ayunan yang condong dan sebagian unit lain sudah berkarat dan rusak. Kemudian APE luar ini juga berada di atas tanah gambut, sehingga berlumpur pada musim hujan dan 
berdebu pada musim kemarau. Hal ini tentunya tidak sesuai dengan prinsip yang diuraiakan dalam Permendiknas No. 58 tahun 2009 yang menjelaskan tentang konsep aman, nyaman, dan memenuhi kriteria kesehatan bagi anak.

Kemudian PAUD Cahaya Insan desa Penebal ini juga merupakan satu-satunya PAUD Nonformal desa yang terletak di jalan utama desa Penebal kecamatan Bengkalis. Lokasi PAUD Nonformal desa ini cukup strategis karena berada di pemukiman penduduk dengan akses yang mudah, namun kurang kondusif karena berada di tepi jalan utama desa yang juga merupakan jalan lintas ke desa lain. PAUD Cahaya Insan desa Penebal ini berada di atas lahan seluas $87 \mathrm{x}$ $50 \mathrm{M}$ dengan status sudah milik sendiri. Di atas lahan tersebut terdapat gedung yang berukuran 26 x 9 M. Ini artinya masih luas ruang terbuka yang tersedia untuk area bermain dan taman.

Gedung PAUD Cahaya Insan desa Penebal ini pada dasarnya mirip dengan bentuk gedung lembaga pendidikan pada umumnya. Namun desainnya sedikit berbeda karena dari warna dan lukisan yang ada di dinding bagian luar memberikan kesan dan ciri khas edukatif bagi anak usia dini. Suyadi (2012) menjelaskan, sebenarnya tidak ada formula yang baku mengenai bentuk gedung PAUD. Namun sebaiknya ada perbedaan dari gedung-gedung lembaga pendidikan lainnya, terutama warna cat didnding, lukisan, yang memikat perhatian anak sehingga mereka dengan mudah menangkap kesan edukatif ketika memasuki lingkungan sekolah.

Selanjutnya berdasarkan hasil pengamatan terhadap pola dan tata ruang di lembaga PAUD Cahaya Insan diketahui bahwa terdapat 2 ruang belajar, kantor, ruang aula, perpustakaan, 2 unit tempat cuci tangan, dan 2 unit kamar mandi (toilet). Ruang bermain dalam terdapat diruang terbuka yang cukup luas yaitu di Aula. Di ruang ini terdapat beberapa rak tempat menata APE dalam, dimana anak leluasa untuk mengguanakan dan menata kembali alat-alat permainannya. Sebagaimana Suyadi (2012) mengatakan bahwa pola tata ruang diharapkan dapat membuat anak mudah mengeluarkan inisiatif, membiasakan hidup tertib, teratur, dan disiplin.

Kemudian di halaman kanan gedung terdapat are bermain yang dilengkapi APE luar yang terdiri dari 3 unit papan ayunan, 2 unit seluncuran, 2 unit kursi jungkit, dan 1 unit papan jungkit dari kayu. Semua unitAPE luar ini masih dalam kondisi yang baik dan terawat, bahkan beberapa unit masih kelihatan baru dipasang. Namun semua unit APE luar ini berada di atas tanah gambut dengan permasalahannya berlumpur pada musim hujan dan berdebu ketika musim kemarau datang. Dengan demikian prinsip aman, nyaman, dan memenuhi kriteria kesehatan bagi anak yang distandarkan belum tercapai.

4. Pendayagunaan Ketatausahaan dan Pengelolaan Keuangan

Ketatausahaan di lembaga pendidikan merupakan tugas dan tanggung jawab tenaga kependidikan, di dalamnya juga termasuk pengelolaan administrasi keuangan. Temuan dalam penelitian ini, PAUD Kasih Bunda desa Teluk Latak dan PAUD Cahaya Insan desa Penebal kecamatan Bengkalis tidak memiliki tenaga adminstrasi yang khusus bekerja dengan urusan ketatausahaan. Tugas dan tanggung jawab administrasi secara rangkap dilakukan oleh pengelola PAUD Nonformal desa ini dengan melibatkan beberapa orang guru. Salah satu kompetensi tenaga administrasi di lembaga PAUD menurut Mulyasa (2012) adalah kompetensi profesional dalam mengelola keuangan sesuai dengan prinsip pengelolaan yang akuntabel, transparan, dan efisien. Pengelolaan keuangan meliputi sumber dana, jenis biaya, dan pertanggung jawaban penggunaan dana.

Temuan dalam penelitian ini pada PAUD Kasih Bunda desa Teluk Latak dan PAUD Cahaya Insan desa Penebal, bahwa kedua PAUD Nonformal desa ini memiliki sumber dana yang berasal dari ADD dan sumbangan orang tua murid dalam bentuk SPP. Dua sumber dana inilah yang dimanafaatkan sebagai biaya investasi dan biaya operasional. Dana yang bersumber dari Alokasi Dana Desa diterima setiap enam 
bulan sekali, sedangkan SPP dari murid diterima setiap bulan. Namun pengelolaan keuangan di kedua PAUD Nonformal desa ini belum profesional dan transparan. Belum terbentuk komunikasi yang positif antara pengelola PAUD Nonformal desa ini dengan masyarakat dan orang tua murid berkenaan dengan pengelolaan keuangan.

Sementara itu dalam Permendiknas No. 49 tahun 2007 tentang standar pengelolaan pendidikan oleh satuan pendidikan nonformal dinyatakan bahwa pengelola satuan pendidikan memiliki kewenangan dan tanggung jawab dalam menggunakan anggaran pendidikan sesuai dengan peruntukaannya. Selanjutnya pelaporan tentang penerimaan dan pengeluaran serta penggunaan anggaran dilaporkan kepada pihak berkepentingan.

Pihak yang berkepentingan dengan dana ADD dan SPP murid yang dikelola oleh PAUD nonformal desa termasuk di dalamnya aparat pemerintah desa, Badan Permusyawaratan Desa (BPD), orang tua wali murid, dan pihak lain yang relevan. Dari hasil wawancara peneliti dengan pihak yang diiutarakan diatas terungkap bahwa pihak lembaga PAUD Kasih Bunda desa Teluk Latak dan PAUD Cahaya kasih desa Penebal tidak melakukan sosialisasi anggaran dan pelaporan sebagaimana mestinya. Dana yang bersumber dari ADD hanya dilaporkan kepada bendahara di kantor desa, sedangkan dana yang bersumber dari SPP murid tidak disosialisasikan pengelolaannya.

\section{Kemitraan}

Dalam Permendiknas No. 49 tahun 2007 tentang standar pengelolaan pendidikan oleh satuan pendidikan nonformal dinyatakan bahwa setiap satuan pendidikan nonformal menjalin kemitraan dengan lembaga lain yang relevan, baik lembaga pemerintah maupun swasta yang ditetapkan dengan perjanjian tertulis. Dengan demikian sebagai lembaga pendidikan nonformal, PAUD Kasih Bunda desa Teluk Latak dan PAUD Cahaya Insan desa Penebal idealnya membangun kemitraan dengan pihak luar yang relevan dengan tumbuh dan kembang anak, seperti pihak dinas kesehatan, lembaga sosial, lembaga agama, dan juga psikolog.

Temuan penelitian pada sub fokus ini dapat dinterpretasikan bahwa PAUD Kasih Bunda desa Teluk Latak dan PAUD Cahaya Insan desa Penebal sudah memiki kemitraan secara teknis dengan beberapa pihak luar. Namun kemitraan yang dibangun sesuai dengan keterbatasan akses tesebut belum dituangkan kedalam sebuah program kerja sama tertulis. Akses kedua lembaga PAUD nonformal desa ini terbatas hanya kepada pihak puskesmas pembantu, dan PKK desa, akan tetapi belum ada sistem kemitraan yang ditetapkan dengan perjanjian tertulis.

\section{SIMPULAN DAN SARAN}

Berdasarkan temuan dan hasil pembahasan penelitian, maka dapat diperoleh kesimpulan bahwa penyusunan kurikulum, dan proses pembelajaran di PAUD Kasih Bunda desa Teluk Latak dan PAUD Cahaya Insan desa Penebal kecamatan Bengkalis sudah baik, namun dalam hal pengembangan bahan ajar belum melibatkan orang tua sesuai dengan prinsip dan standar yang terdapat dalam Permendiknas No. 58 tahun 2009 tentang standar PAUD.Tenaga pendidik dan kependidikan di PAUD Kasih Bunda desa Teluk Latak dan PAUD Cahaya Insan desa Penebal kecamatan Bengkalis belum memenuhi kualifikasi akademik sebagaiman yang diamanatkan Permendiknas No. 58 tahun 2009 tentang standar PAUD.

Pendayagunaan sarana dan prasarana di PAUD Kasih Bunda desa Teluk Latak dan PAUD Cahaya Insan desa Penebal kecamatan Bengkalis sudah baik dan layak dari segi kelengkapan, akan tetapi belum sesuai dengan prinsip aman, nyaman, dan memenuhi kriteria kesehatan bagi anak berdasarkan Permendiknas No. 58 tahun 2009 tentang standar PAUD. Ketatausahaan dan pengelolaan keuangan di PAUD Kasih Bunda desa Teluk Latak dan PAUD Cahaya Insan desa Penebal kecamatan Bengkalis belum profesional, dan belum 
tercapainya pengelolaan keuangan yang transparan dan akuntabel berdasarkan standar yang tertuang dalam Permendiknas No. 49 tahun 2007 tentang standar pengelolaan pendidikan oleh satuan pendidikan nonformal. Kemitraan yang dibangun oleh lembaga PAUD Kasih Bunda desa Teluk Latak dan PAUD Cahaya Insan desa Penebal kecamatan Bengkalis masih dalam lingkup desa, dan belum dituangkan ke dalam program kerja sama dan perjanjian tertulis.

\section{Saran}

Bertolak dari simpulan di atas, maka peneliti memiliki saran dalam penyelenggaraan PAUD Nonformal desa di kecamatan Bengkalis yakni berkenaan dengan pencapaian penyelenggaraan PAUD nonformal desa di kecamatan Bengkalis untuk penyusunan dan pelaksanaan kurikulum dapat menjadi dasar perbaikan, pemberian dorongan, dan stimulasi oleh pengawas PAUD nonformal terhadap pengelola dan guru PAUD nonformal desa di kecamatan Bengkalis, khusunya PAUD Kasih Bunda desa Teluk Latak dan PAUD Cahaya Insan desa Penebal untuk mencapai standar yang telah ditentukan. Pemerintah dalam hal ini pemerintah daerah melalui SKPD yang berwenang dalam penyelenggaraan PAUD nonformal desa agar mengambil langkah bijak dengan menyusun program yang tepat untuk pemenuhan kualifikasi akademik tenaga pendidik dan kependidikan PAUD nonformal desa di kecamatan Bengkalis untuk mencapai standar yang telah ditetapkan.

Pengelola PAUD nonformal desa khususnya PAUD Kasih Bunda desa Teluk Latak dan PAUD Cahaya Insan desa Penebal agar menjalin komunikasi yang intensif dengan masyarakat desa dalam pemenuhan sarana dan prasarana PAUD agar sesuai dengan standar dan prinsip yang ditetapkan. Pengelola PAUD nonformal desa kecamatan Bengkalis khusunya PAUD
Kasih Bunda dan PAUD Cahaya Insan agar dapat mendudukkan tenaga profesional khusus dalam urusan administrasi dan pengelolaan keuangan dengan membangun komunikasi yang positif terhadap semua pihak yang peduli dengan perkembangan PAUD desa untuk terciptanya pengelolaan keuangan yang transparan dan akuntabel. Perlu wadah dan usaha untuk belajar menuangkan sebuah aktivitas kerja sama lembaga PAUD nonformal desa dengan pihak luar yang relevan kedalam sebuah program kerja sama dan memiliki perjanjian tertulis.

\section{DAFTAR PUSTAKA}

Aedi. Nur. 2014. Pengawasan Pendidikan; Tinjauan Teori dan Praktik. Jakarta; P.T. Rajagrafindo Persada.

Asmani. Jamal. 2009. Manajemen Strategis Pendidikan Anak Usia Dini. Yogyakarta: Diva Press.

Basrowi dan Suwandi. 2008. Memahami Penelitian Kualitatif. Jakarta: Rineka Cipta.

Mulyasa. 2012. Manajemen PAUD. Bandung: P.T Remaja Rosda Karya.

Permendiknas Nomor: 58 tahun 2009 tentang standar Pendidikan Anak Usia dini. Nomor: 49 tahun 2007 tentang standar pengelolaan pendidikan oleh satuan pendidikan Nonformal.

Patilima, Hamid. 2011. Metode Penelitian Kualitatif. Jakarta: Alfabeta.

Sobry. S. 2012. Manajemen Pendidikan, Langkah praktis Mewujudkan Lembaga Pendidikan yang Unggul. Lombok: Holistica.

Suyadi. 2011. Manajemen PAUD, Mendirikan, Mengelola, dan Mengembangkan PAUD. Yogyakarta: Pustaka Pelajar. 